\title{
MORFOLOGIA DE FEIÇÕES GEOMORFOLÓGICAS PERIGLACIAIS E PROGLACIAIS DA PENÍNSULA FILDES
}

\author{
Carina Petsch $^{(\mathrm{a})}$, Katia. Kellem da Rosa ${ }^{(\mathrm{b})}$, Carolina Lorens Simões ${ }^{(\mathrm{c})}$, Jeferson Cardia \\ Simões ${ }^{(d)}$ \\ (a, b, c, d) Programa de Pós Graduação em Geografia, Universidade Federal do Rio Grande do Sul, Email: \\ carinapetsch@gmail.com; katiakellem@gmail.com; carolina.1simoes@gmail.com; jefferson.simoes@ufrgs.br
}

EIXO: SISTEMAS GEOMORFOLÓGICOS: ESTRUTURA, DINÂMICAS E PROCESSOS

\begin{abstract}
Resumo
A medida que uma geleira retrai expõe feições do terreno que são retrabalhadas pela ação intempérica, e por processos glacio fluviais e glacio marinhos. Dessa forma, é objetivo dessa pesquisa identificar feições decorrentes da retração da geleira Collins na península Fildes, Antártica. Foram realizados dois trabalhos de campo em 2015 e 2016, onde as feições foram fotografadas e tomado o ponto de GPS. Para as feições proglaciais foram coletadas amostras sedimentares para análise granulométrica e morfoscópica. No setor ao sul e central na península encaixam-se vales esculpidos por fluxos de gelo que se divergiam de acordo com a topografia local. No setor norte há um cordão morâinico de avanço, da Pequena Idade do Gelo, flutings e morainas supraglaciais sujeitas a ablação sazonal que indicam uma fase de retração recente da frente da geleira Collins. As feições identificadas servirão para interpretação e mapeamento geomorfológico de detalhe de toda península.
\end{abstract}

Palavras chave: morfologia, periglacial, proglacial, vales, Fildes.

\section{Introdução}

Conforme uma geleira retrai, o terreno começa a sofrer processos de retrabalhamento pela ação do vento, fluxos gravitacionais, fluvial, precipitação líquida e consequente intemperismo químico e físico dos depósitos recentemente expostos (MERCIER, 2008; MERCIER e ÉTIENNE, 2008) permitindo que a dinâmica das geleiras possa ser inferida a partir da interpretação das geoformas deposicionais destes ambientes (FOUNTAIN e WALDER, 1998). O estudo desses aspectos auxilia no entendimento do comportamento e padrão de retração e das respostas do ambiente a processos posteriores de retrabalhamento visando uma comparação com outras áreas da região marítima antártica.

A atividade paraglacial é considerada por Benn e Ballantyne (1994) como um dos primeiros efeitos das mudanças ambientais na zona proglacial e a formação de morainas evidencia o padrão de avanço/retração das geleiras (BENN e EVANS, 2010). Uma moraina é uma forma resultante de deposição e ou deformação de sedimentos transportados por uma geleira. Existem diferentes tipos de geleiras que ocorrem devido processos variados que ocasionam deposição de sedimentos em ambientes geograficamente diferentes (GOUDIE, 2004). Morainas podem ser classificadas de acordo com a gênese como de empurrão, compreensão ou despejo e geograficamente de acordo com a posição no sistema glacial (BENN e EVANS, 2010; GOUDIE, 2004). A feição exterior formada no limite 
OS DESAFIOS DA GEOGRAFIA FÍSICA NA FRONTEIRA DO CONHECIMENTO

Instituto de Geociências - Unicamp

Campinas - SP

28 de Junho à 02 de Julho de 2017

frontal marginal da geleira é classificada como moraina terminal, que podem estar ligadas à períodos de estabilizações durante avanços. Também podem ocorrer morainas mediais, laterais e ainda laterofrontais.

O ambiente proglacial, formado pela recente retração glacial, possui uma dinâmica complexa em geleiras temperadas com intenso fluxo de água de degelo. Entre os distintos processos glaciais, relacionam-se glaciofluviais, glaciolacustres e glaciomarinhos além de depósitos morâinicos, flutings e eskers (GOUDIE, 2004; BENN e EVANS, 2010). A medida que a geleira retrai a zona proglacial se modifica para periglacial, já que não há mais ligação hidrológica-sedimentar com o sistema glacial. Objetivo desse trabalho é identificar morfologias do ambiente periglacial e proglacial da Península Fildes buscando entender a deglaciação da área.

\section{Caracterização da área}

A retração das geleiras acarreta o surgimento e expansão das áreas livres de gelo, que, segundo Bockheim e Hall (2002), representam menos de 1\% de todo continente antártico. Desta proporção, 14\% estão na Península Antártica e suas ilhas. A península Fildes (Figura 01), parte da ilha Rei George, está entre as latitudes $62^{\circ} 08^{\prime}$ e $6^{\circ} 14^{\prime}$ Sul e longitudes $59^{\circ} 02^{\prime}$ e $58^{\circ} 51^{\prime}$ Oeste e foi uma das primeiras áreas a sofrer exposição, dentro do arquipélago das Shetland do Sul, depois do Último Máximo Glacial. Barsh e Maüsbacher (1986) concluíram que a deglaciação da área ocorreu antes de 6000 anos A.P. No Holoceno Tardio, à frente da geleira se manteve praticamente estável, com recuo não ultrapassando poucas dezenas de metros.

As ilhas do arquipélago Shetland do Sul são separadas da América do Sul pelo Mar de Drake, e da Península Antártica pelo Estreito de Bransfield. As ilhas pertencem a um grupo de ilhas que, supostamente, compartilham a mesma história geológica e tectônica. As Ilhas Shetland do Sul podem conter rochas vulcânicas e plutônicas do Cretáceo Inferior e do início do Mioceno, relacionada à subducção do Pacífico abaixo do continente antártico (SMELLIE, 1983). Vulcanismo subsequente do Mioceno (BIRKENMAJER et al., 1990) está associado a rifteamento no Estreito de Bransfield. A Península de Fildes é composta por uma espessa sucessão de basalto e andesito com intercalações de rochas vulcanoclásticos (HAWKES, 1961).

A geleira Collins é um pequeno domo de gelo aproximadamente na latitude $62^{\circ} 12^{\prime} \mathrm{S}$ e longitude $58^{\circ} 57^{\prime} \mathrm{W}$, com $15 \mathrm{~km}^{2}$ de área e altitude máxima de $270 \mathrm{~m}$ (SIMÕES et al, 2015), localizado ao norte da península Fildes. 


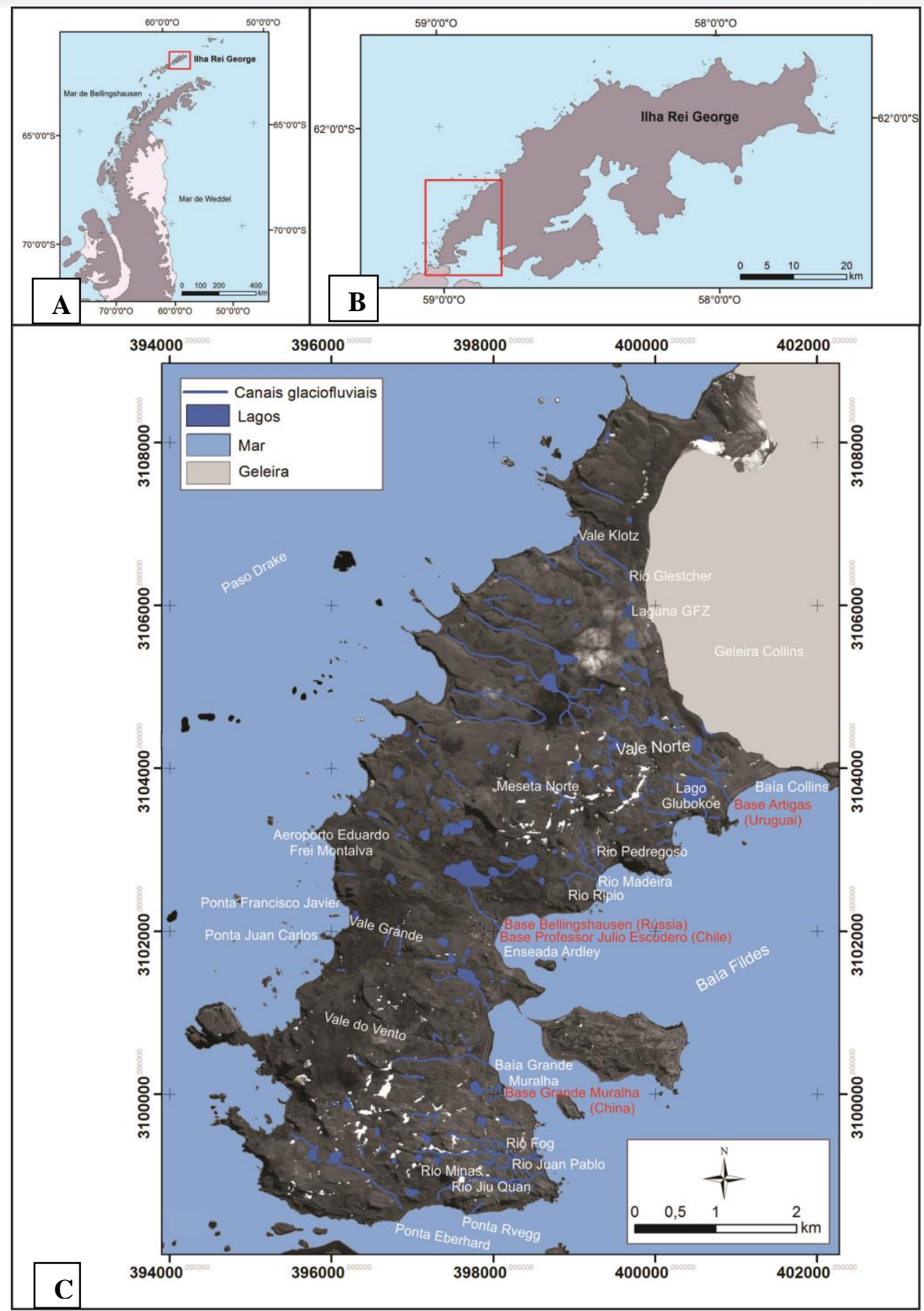

Figura 01: A - Península Antártica com quadro em vermelho delimitando a ilha Rei George; B - Ilha Rei George com quadro em vermelho destacando a península Fildes; C - Península Fildes com as principais toponímias utilizadas nesse trabalho.

\section{Materiais e métodos}

As atividades de campo foram realizadas nos verões 2015 e 2016. Para a zona periglacial foi realizada uma análise das formas, com uso de fotografias, análise do ambiente, presença de estrias nas 
rochas e outras evidências da deglaciação da área. Para a zona proglacial além dos critérios citados acima, também foram coletadas amostras sedimentares:

- Procedimentos para a análise granulométrica: As amostras foram coletas na quantidade de 100 gramas. A separação dos finos e grossos ocorreu através de uma peneira com malha 0.062 (escala Wentworth e Stokes) pelo processo seco. O material retido na peneira foi considerado "grosso" e submetido a peneiramento em um conjunto de peneiras com a malha decrescente até o limite de 0,062 mm, para que haja a separação de acordo com classes texturais. Em seguida realizou-se a pesagem por classe.

- Procedimentos para a análise morfoscópica: a análise foi realizada em 50 graus das três classes granulométricas de maior intervalo. A análise do grau de arredondamento foi realizada usando a tabela de comparação de Krumbein (1941) e o grau de esfericidade medido através da tabela de Rittenhouse (1943). A forma do clasto foi definida pela dimensão relativa dos três eixos ortogonais, chamados $a$ (maior), $b$ (intermediário), e $c$ (menor) (HUBBARD e GLASSER, 2005).

\section{Resultados}

Os resultados indicam que a península Fildes é caraterizada por diferentes setores, um ao norte proximal a geleira Collins e um mais ao sul deglaciado há mais tempo. No setor ao sul e central na península encaixam-se vales esculpidos por fluxos de gelo que se divergiam de acordo com a topografia local. No setor norte há vales encaixados topograficamente e morainas supraglaciais e flutings recentes (últimos 20 anos) demarcando a retração recente da frente do sistema glacial.

\section{Zona Proglacial}

A margem da geleira em retração é marcada por morainas e por nunataks (picos rochosos no gelo). Junto à laguna GFZ há uma área rochosa de alta topografia que divide os fluxos da geleira Collins para oeste (Vale Klotz) e para leste (vale Vale Norte) na península formando dois vales erodidos pela ação glacial e atualmente por fluxos fluviais evidenciando um ambiente transitório para periglacial.

A Meseta Norte, com altitudes chegando a 155 metros de atitude em relação ao nível do mar, atua como uma porção rochosa dispersora de fluxos de gelo acumulados nas áreas de topografia mais alta. Desta forma, formaram-se fluxos de gelo registrado pelos vales em forma de $\mathrm{U}$ erodidos, que se dirigiam para o noroeste, como o vale Klotz e o vale Norte. Ambos os vales possuem registros de feições morâinicas nas suas porções laterais, assim como blocos rochosos erodidos. $\mathrm{O}$ vale Klotz de alinhamento Sudeste-Noroeste possui altitudes no seu centro que variam em torno de 15 metros em relação ao nível do mar e o Vale Norte possui altitudes em sua porção central de aproximadamente 20 metros de altitude e com a formação de um lago nas áreas de menores cotas altimétricas. Fluxo de 
OS DESAFIOS DA GEOGRAFIA FÍSICA NA FRONTEIRA DO CONHECIMENTO Instituto de Geociências - Unicamp Campinas - SP

28 de Junho à 02 de Julho de 2017

detritos e canais fluviais inseridos nestes vales provocam o retrabalhamento das feições deposicionais e erosivas. Junto às porções laterais ao sul do vale Klotz há falésias que podem representar ação erosiva do mar junto ao Estreito de Drake, assim como a deposição de seixos e cascalhos por longa extensão do vale indicam a ação marinha de áreas localizadas atualmente em cotas altimétricas de em torno de 14 metros de altitude.

Em toda a enseada na maioria das áreas livres de gelo há lagos de água de degelo e canais. Esses lagos e alagadiços formam-se principalmente próximo às margens frontais da geleira. O influxo de água de degelo gerado para esses lagos é essencialmente da água de degelo na neve e fusão da geleira. Os setores de acumulação de neve que perduram por mais tempo no verão estão inseridos junto as vertentes orientadas para o sul na península.

Os depósitos identificados como flutings (Fotografia C - Figura 2) possuem em média $2 \mathrm{~m}$ de altura e 4-5 m de extensão e assim como denotam Bennett e Glasser (1996) possuem uma secção transversa uniforme que geralmente se inicia por um obstáculo rochoso. $\mathrm{O}$ índice $\mathrm{C}_{40}$ entre 10 e 26 indica uma média a alta distância de transporte glaciofluvial e ou subglacial para a modificação do grão, contudo outras características apresentadas indicam que a amostra possui mistura de sedimentos de diferentes tempos de transporte. Isso se evidencia na amplitude de valores encontrados para o índice RA, com arredondamento variando entre 6 e $70 \%$, ou seja, feições com material com boa esfericidade variando até esfericidade baixa. Estão localizados na área proglacial de contato com o gelo em um ambiente recentemente exposto, em uma área com formação de vários canais de água de degelo, e de acordo com a retração frontal da geleira têm-se o aparecimento dessas feições em maior número.

Morfologicamente as morainas supraglaciais (Fotografia D - Figura 2) apresentam se em montículos com 1-2 $\mathrm{m}$ de altura e até $5 \mathrm{~m}$ de comprimento. Quanto a granulometria predomina cascalhos, e arredondamento prevalece na classe sub-angular, com índice RA entre 45 e $48 \%$, enquanto a esfericidade predomina em média a baixa entre 38 e 45 . Pouco selecionamento, esfericidade e arredondamento são características de transporte passivo e pouca distância de transporte após o arrancamento do substrato e fraturamento dos grãos por intemperismo físico pós-deposicional evidenciado. A alta angularidade e pouca esfericidade podem resultar da grande quebra que sofrem os grãos. A formação das morainas supraglaciais na área de estudo mostram estarem relacionadas a processos de empurrão e compressão, na presença de obstáculo rochoso local, e à diminuição da espessura em setores frontais com estagnação do fluxo de gelo.

Morainas de recessão (Fotografia B - Figura 2) condicionadas à época de ablação se apresentam em formato de montículo não formando uma crista morâinica, com $1 \mathrm{~m}$ de altura e comprimento máximo em 4 m. Os valores de $\mathrm{C}_{40}$ (6 e 20) são relativamente baixos, com grãos de esfericidade média predominando e o índice RA varia entre 1 e 30\% com material variando entre subangular e sub arredondado e quanto a granulometria há predominância de cascalho. A tendência de ser predominantemente de grãos grosseiros e pouca quantidade de tamanhos finos e o selecionamento 
XVII Simpósio Brasileiro

de Geografia Física Aplicada

I Congresso Nacional

de Geografia Física

\section{OS DESAFIOS DA GEOGRAFIA FÍSICA NA FRONTEIRA DO CONHECIMENTO \\ Instituto de Geociências - Unicamp \\ Campinas - SP \\ 28 de Junho à 02 de Julho de 2017}

indica que a amostra possui características de sedimentos predominantemente modificados por processos erosivos em ambiente englacial e supra glacial ou pouca distância de transporte para a modificação dos grãos. Esses cordões de menor extensão lateral e descontínuos representam deposições da recente fase de recessão da geleira.

A crista morâinica de avanço (Fotografia A - Figura 2) comumente mostra-se $10 \mathrm{~m}$ acima do nível gelo atual e parte desta pode ter sido formada por processo de empurrão durante a fase de avanço, e já se encontra retrabalhada. Possui índice $\mathrm{C}_{40}$ variando entre 22 e 25 , esfericidade entre baixa e média e o índice RA varia entre 38\% e 64\% evidenciando material imaturo com pouco tempo de transporte com material supraglacial, embora apresente variação na composição deposicional podendo ser encontrado till subglacial. Quanto a granulometria há predominância de cascalho. Por sua localização, podem ser interpretadas como morainas de avanço. Datações indicam avanço da geleira Collins contemporâneas a Pequena Idade do Gelo, há aproximadamente 650 anos atrás (HALL et al. 2007).

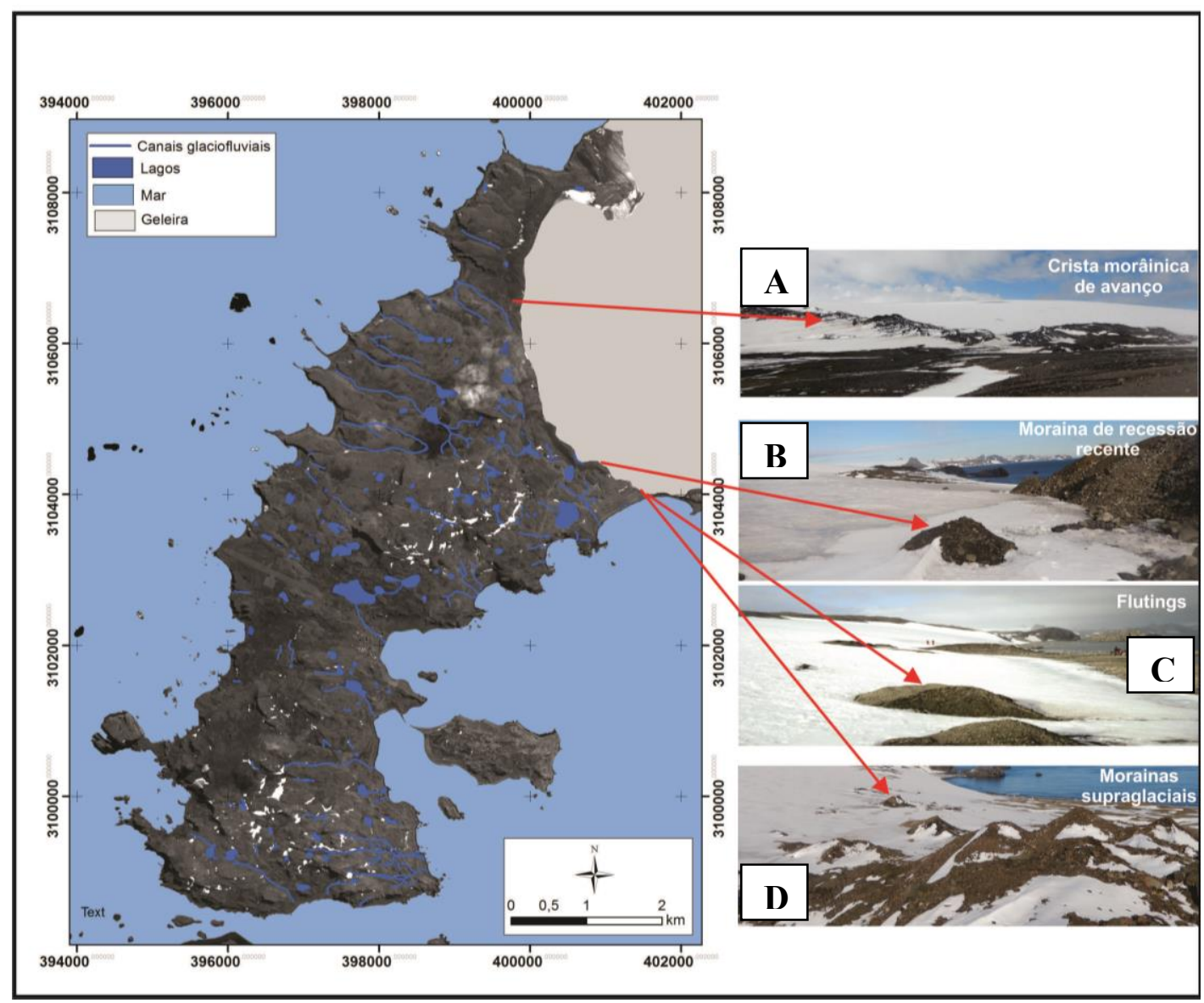

Figura 02: Feições proglaciais encontradas na Península Fildes. A - cristas morâinicas de avanço; B morainas de recessão recentes; C - flutings; D - Morainas supraglaciais. 


\section{Zona periglacial}

No setor oriental da Meseta Norte há um setor rochoso erodido formando um vale em direção à leste para a baía Fildes. E onde atualmente drenam-se vários canais, como o rio Ripio, Pedregoso, Madeira. O vale chega a altitudes de 75 metros nas laterais (nos setores soerguidos vistos de Escudeiro) e de entorno de 25 metros de altitude na porção central.

Na porção central, próximo a pista do aeroporto há a formação de lagos interconectados por canais de fusão que fluem das porções ao sopé da meseta Norte para a enseada Ardley (Fotografia 7 - Figura 03). Ao sopé da meseta Norte há um setor de maior declividade que forma um vale em circo (Fotografia 2 - Figura 03), registrando a erosão por uma geleira de circo que anteriormente fluía ao longo do vale até a zona costeira. As margens deste fluxo ao sul estão relacionadas a formação rochosa denominada Meseta Cruz.

$\mathrm{Na}$ porção central junto, em direção ao Drake há a formação de um vale de deposição fluvial de sedimentos derivados das áreas marginais mais altas. $\mathrm{O}$ vale é chamado vale Grande e possui cotas que variam suavemente formando um sistema deltaico com grande acumulação de sedimentos finos em direção à zona costeira. $\mathrm{O}$ vale pode ter sido esculpido pela ação de um fluxo glacial que drenava no sentido Leste-Oeste desprendendo-se na enseada Elefantes Marinhos. Na enseada há dois promontórios rochosos denominados ao sul de Ponta Juan Carlos e ao norte de Ponta Francisco Javier, as quais podem estar relacionadas a ponto de ancoragem de um fluxo de uma geleira que chegava ao mar.

Em direção ao sul da península, em um setor descrito como o Vale do Vento, há um vale encaixado entre duas porções rochosas de maior altitude (chegando a 130 metros de altitude). Deste vale atualmente drenam canais de fusão que contribuem para o escoamento do rio Vento, o qual flui para o setor leste da península para a Bahia Grande Muralha. O vale do vento bifurca-se para a porção ocidental da península, junto a acumulações sazonais de neve.

Acompanhando estas zonas de fraqueza estruturais geológica da península Fildes, insere-se no sentido Leste-Oeste um extenso vale ao sul da península. Neste vale em forma de "U" erodido glacialmente (Fotografia 3 - Figura 03), atualmente há retrabalhamento pela ação fluvial e há a acumulação de água de fusão e de sedimentos nas porções de menor altitude através de lagos. Na margem ao sul, junto a parte costeira há deposição sedimentar mais espessa indicando morainas marginais do fluxo de gelo pretérito. Foram encontrados blocos com formato de stoss and lee retrabalhados pela ação marinha sendo não observados estriamentos.

Voltado para o Sul há um vale na forma de circo que representa condições de erosão glacial com a formação de um lago na porção central mais rebaixada do terreno (Fotografia 4 - Figura 03). Há paredes rochosas íngremes com fluxo de detritos. Com o retrabalhamento pela ação fluvial e marinha 
XVII Simpósio Brasileiro

de Geografia Física Aplicada

I Congresso Nacional

de Geografia Física

\section{OS DESAFIOS DA GEOGRAFIA FÍSICA NA FRONTEIRA DO CONHECIMENTO \\ Instituto de Geociências - Unicamp \\ Campinas - SP \\ 28 de Junho à 02 de Julho de 2017}

há sedimentos arredondados no leito do vale. As pontas Rvegg e Eddy podem representar a extensão lateral do fluxo glacial que se inseria no local.

Acompanhando os falhamentos tectônicos existentes ao sul da península dois vales em forma de $\mathrm{U}$ se encaixam na direção Oeste-Leste (Fotografia 6 - Figura 03). Os vales possuem sistemas de drenagens fluviais extensos (rio Minas e Jiu Quan e ainda os rios Fog e Juan Pablo) e a deposição lagunar na parte central. Também evidenciam processos de fluxo de detritos e ação de intemperismo químico e físico. No vale mais ao sul, junto a costa, foi encontrado um bloco stoss and lee estriado que demonstra a existência de um fluxo de gelo na direção em que se se encaixa o vale em forma de $\mathrm{U}$ (Fotografia 5 - Figura 03).

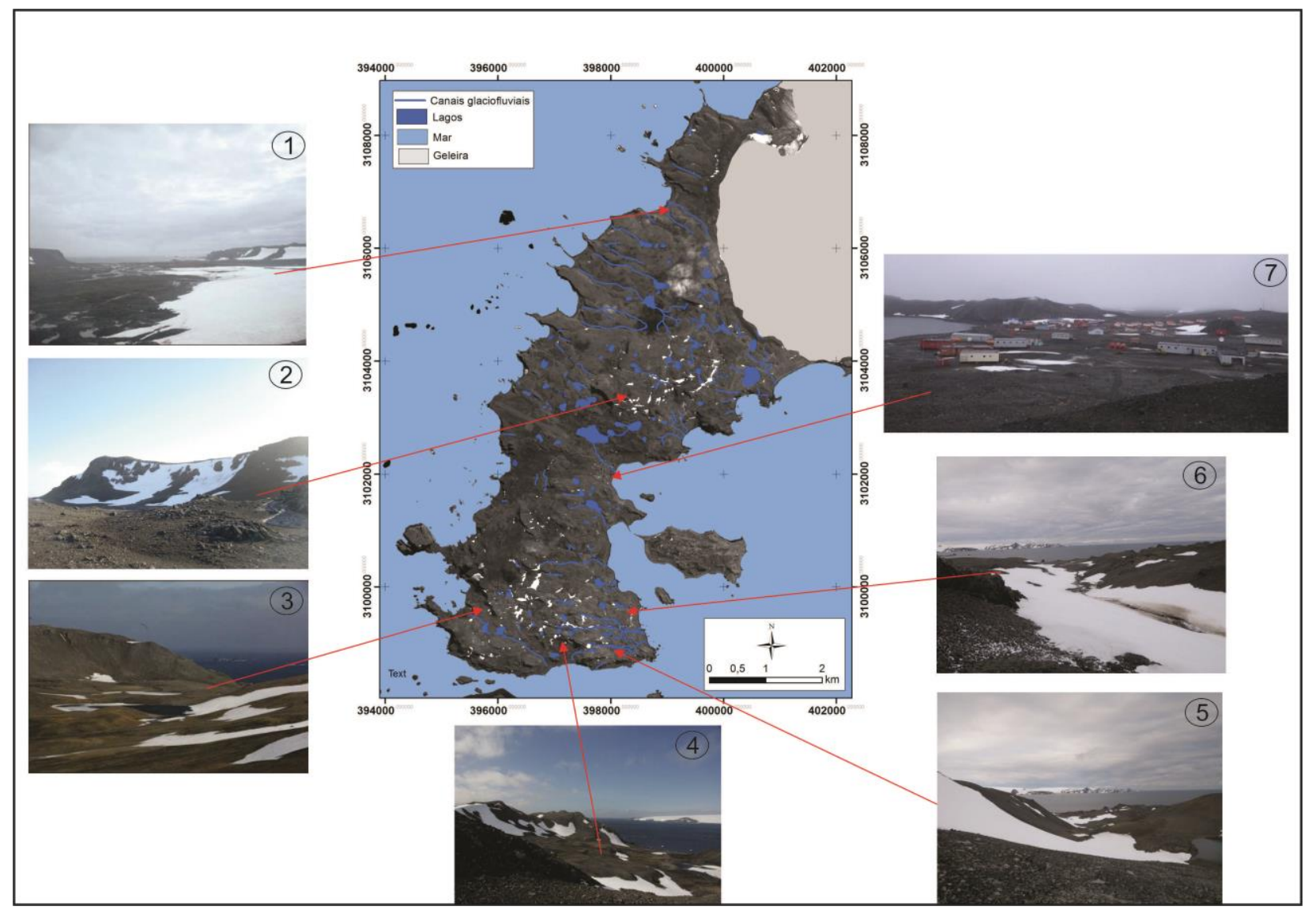

Figura 03: Principais vales da Península Fildes.

Cordões litorâneos são perceptíveis ao longo de toda a porção costeira da península Fildes e são caracterizados pela deposição de material sedimentar erodido pela ação do mar e encontram-se alinhados paralelamente a linha de costa atual. Essas feições são evidências das mudanças do nível do mar no ambiente. Estas áreas não são associadas a glaciação recente devido à ausência de processos de retrabalhamento glacial (ROSA et al., 2010). 


\section{Conclusões}

A geleira Collins, apresenta na zona proglacial feições geomorfológicas que denotam um sistema em retração pela presença de flutings, formados pelo preenchimento de canais de degelo por sedimentos e também pelo número significante de morainas de recessão condicionadas ao período de ablação em zonas de menor espessura da geleira.

Há elevada atividade periglacial como gelifluxão na porção central e sul da Península. Seixos e cascalhos arredondados registram a ação marinha em setores de praias elevadas em relação ao nível do mar. Blocos stoss and lee foram registrados junto a porção central dos vales na parte ao sul da península Fildes. Junto às áreas elevadas há acelerado processo de intemperismo físico e também em menor grau de intemperismo químico. E fluxos de detritos e fluxo de água de degelo transportam estes materiais para as áreas mais baixas dos vales.

Os registros geomorfológicos encontrados nos ambientes de deglaciação da península Fildes foram úteis para a interpretação dos processos erosivos e deposicionais glaciais passados, tais como processos erosivos e de intemperização recentes que causam o retrabalhamento dos depósitos.

As feições identificadas serão utilizadas para posterior mapeamento geomorfológico de toda península, onde serão descritos além da forma, processos de formação e evolução do ambiente em caso de continuidade na retração da geleira e evolução de sua área proglacial.

\section{Referências}

BARSH, D.; MAUSBACHER, R. New data on the relief development of the South Shetland Islands, Antarctica. Interdisciplinary Science Review, v. 11, p. 211-219, 1986.

BENN, D. I.; BALLANTYNE, C. K. Reconstructing the transport history of glaciogenic sediments - a new approach based on the covariance of clast form indices. Sedimentary Geology, v. 91, n. 1-4, p. 215-227, 1994.

BENN, D.I.; EVANS, D. J. A. Glaciers and Glaciation. London: Arnold, 734 p. 2010.

BENNETT, M. R.; GLASSER, N. F. Glacial Geology - Ice Sheets and Landforms. England: John Wiley \& Sons Ltd. 364 p, 1996.

BIRKENMAJER, K., SOLIANI, E., KAWASHITA, K. Reliability of Potassium argon dating of CretaceousTertiary island-arc volcanic suites of King George Island, South Shetland Islands (West Antarctica). Bulletin Acaddemic Polonish. Science, v. 30, p. 133-143, 1990.

BOCKHEIM, J. G.; HALL, K. J. Permafrost, active-layer dynamics and periglacial environments of continental Antarctica. South African Journal of Science. n. 98. p. 82-90, 2002.

FOUNTAIN, A. G. WALDER, J. S. Water flow through temperate glaciers. Review of Geophysics, v. 36 (3), p. 299-328, 1998

GOUDIE, A. S. (Ed.) Encyclopedia of Geomorphology. Taylor e Francis e-Library, 2004.

HALL, B. Late-Holocene advance of the Collins Ice Cap, King George Island, South Shetland Islands. The Holocene, v. 17, p. 1253-1258, 2007.

HAWKES D. D. The geology of South Shetland Islands. I, The petrology of King George Island. Scientific Reports of the Falkland Islands Dependencies Survey, v. 26, p. 1-28, 1961.HUBBARD, B.; GLASSER, N. 
Field Techniques in glaciology and glacial geomorphology. John Wiley \& Sons Ltd, West Sussex, 400 p. 2005.

KRUMBEIN, W. C. Measurement and geological significance of shape and roundness of sedimentary particles. Journal of Sedimentary Petrology, v. 11, p. 64-72, 1941.

MERCIER, D. (ed.) Paraglaciaire et changements climatiques, Bulletin de l'Association de Géographes Français, v. 2, p. 131-208, 2008.

MERCIER, D., ÉTIENNE, S. (Ed.) Paraglacial geomorphology: processes and paraglacial context, Geomorphology, v. 95, p. 1-10, 2008.

RITTENHOUSE, G. A visual method of estimating two-dimensional sphericity. Journal of Sedimentary Petrology, v. 13 (2), p. 79-81. 1943.

ROSA, K. K.; VIEIRA, R.; FERRANDO, F. A.; SIMÕES, J. C. Geomorfologia e sedimentologia glacial aplicadas na reconstrução da evolução do ambiente de deglaciação da geleira Wanda, Ilha Rei George, Antártica. Revista Brasileira de Geomorfologia, v. 11, p. 39-48, 2010.

SIMÕES, C. L.; ROSA, K. K.; CZAPELA, F.; VIEIRA, R.; SIMOES, J. C. Collins Glacier Retreat Process and Regional Climatic Variations, King George Island, Antarctica. Geographical Review, v. 105, p. 462-471, 2015.

SMELLIE, J. L. Syn-plutonic origin and Tertiary age for the Pre-Cambrian False Bay schists of Livingston Island, South Shetland Islands. British Antarctic Survey Bulletin, v. 52, p. 21-32, 1983. 